\title{
How to eradicate canine rabies: a perspective of historical efforts
}

\author{
Merritt Clifton \\ PO Box 960, Clinton, Washington 98236, USA. E-mail: anmlpepl@whidbey.com
}

September 28, 2011 will mark the fifth annual celebration of World Rabies Day, a public education event declared by the Alliance for Rabies Control in 2007. This is of special concern to Asia because Asia has more confirmed rabies cases and human rabies deaths than all the rest of the world combined [1]. Formed in 2007, the Alliance for Rabies Control is a non-profit organization dedicated to the proposition that canine rabies, in particular, can be eradicated through the same sort of concentrated effort that eradicated smallpox in 1980, after a 22-year effort led by the World Health Organization [2, 3]. The World Health Organization has hoped for decades to eradicate rabies in the same manner as smallpox, but as an entity working closely with national governments, it has had constrained ability to do the advocacy work undertaken by the Alliance for Rabies Control, which primarily represents concerned individual scientists. The Alliance for Rabies Control hopes to encourage repetition of the international cooperation and attention to targeted high-volume vaccination, which between 1975 and 1980, brought the international anti-smallpox campaign to a successful close in only six years, following 16 years of sporadic gains and losses. The occurrence and nature of these setbacks include lessons applicable to advancing the eradication of canine rabies. Though the numbers of human rabies cases are disputed, with estimates widely varying by source, India is generally recognized as leading the world in canine rabies cases and human rabies deaths, followed (not necessarily in order) by Bangladesh, China, Indonesia, and Pakistan. India was also historically the primary smallpox reservoir. Both, globally and in India, more smallpox cases occurred in 1974, the 16th year of the WHO-led smallpox eradication drive, than in any year since 1951 . Appearing to be headed toward ignominious failure, WHO instead learned from mistakes, restructured the anti-smallpox campaign to better emphasize educating the public and local governments about the need to vaccinate, and in 1975 achieved a reduction in smallpox cases of more than $90 \%$, in India and worldwide.

The prescription for eradicating canine rabies has already been on the table for at least 90 years. As BBC News headlined worldwide on September 8, 2007, the first World Rabies Day, rabies could be wiped out across the world if sufficient vaccinations are carried out on domestic dogs. The possibility of eradicating canine and some other rabies strains through targeted mass immunization has been under discussion among public health veterinarians and animal advocates for at least as long as the notion of eradicating smallpox has been discussed. Contra Costa County, California livestock commissioner J.J. Hogarty testified at a July 1922 public hearing that "Ever since the infectious nature of rabies has been recognized, the efforts of investigators have been directed toward its control and suppression. Legislative measures have been enacted, and quarantine and muzzling orders issued, yet all of the efforts toward eradication of the disease have failed," except through the use of vaccination. "The cost of vaccination is nominal and its administration is accomplished by a simple hypodermic injection that can be done by lay persons," Hogarty explained. "No reaction follows, and the animal is not inconvenienced in the least. Everyone interested in dogs should impress owners of the advantage of having their dogs protected against rabies," Hogarty emphasized and asked that antirabies vaccination be made mandatory. Hogarty cited the success of a dog vaccination program in England, which had inoculated more than 35,000 dogs against rabies, with only one rabies case occurring among them [4]. Rabies vaccination was gradually made mandatory throughout the U.S., at first in individual communities, and later at the state level. Newspaper coverage at www.NewspaperArchive.com indicates that at least 150 cities and counties required rabies vaccination by 1935 . Requirements for rabies 
vaccination appear to have been in place almost everywhere in the U.S. by 1955 . Some resistance to vaccination was apparent, especially in Arizona, where more than three years of lawsuits followed the passage of a state law mandating rabies vaccination in 1945 [5]. However, especially after World War II (19411945), when about $20 \%$ of the U.S. male population were vaccinated against various diseases in connection with military service (16 million men and women of a total U.S. population of just under 140 million served), compliance soared. Onandaga County Animal Disease Control Bureau chief Albert Merry complained in 1951 that "only" $61 \%$ of the dog population of Syracuse, New York, had been vaccinated. That was a rate of success that even today would far exceed the vaccination rate in most of the world beyond U.S. and Europe. Furthermore, it would slightly exceed the current vaccination rate in much of the U.S. and all of Japan [6-8].

U.S. Centers for Disease Control rabies program chief, Charles Rupprecht on the first World Rabies Day in 2007, formally pronounced the U.S. free of canine rabies, but similar informal proclamations had been issued for years [2]. In 1955, when requirements for rabies vaccination of dogs became universal throughout the U.S., public health and animal control officials identified approximately 2,800 canine rabies cases. Only five years later, there were fewer than 700. Between 1970 and 1990, there were fewer canine rabies cases every year. The canine rabies virus was last detected in the U.S. in 2004. [9, 10] The U.S. success in eradicating canine rabies was neither unprecedented nor unparalleled. Britain has been officially free of canine rabies since 1922. Japan, which never had very much canine rabies and had very few dogs relative to human population until recent years, eradicated it in 1956 [8]. Four other island nations-Taiwan, Hong Kong, Malaysia (partially peninsular), and Singapore-have been officially free of canine rabies since 1968.

However, the lessons from successful rabies eradications have often been misread. Mass vaccination of dog populations, in particular, is neglected in favor of futile attempts to exterminate dogs. Vaccination efforts in India, Bangladesh, China, Indonesia, Pakistan, and much of the rest of the developing world focus on providing post-exposure treatment to the human victims of bites by suspected rabid dogs. Indeed, post-exposure vaccination saves thousands of lives annually, despite many failures when dog bite victims fail to seek treatment soon enough, do not complete the full course of injections, or receive fake, expired, or obsolescent vaccines. The latter problems remain dismayingly common in parts of India, China, Nigeria, and Indonesia, where post-exposure vaccines are often made by local suppliers, using formulas elsewhere long abandoned [11, 12, 13]. Postexposure vaccination is essential, and must continue, using up-to-date vaccines and protocols to achieve consistently positive results. However, post-exposure vaccination contributes nothing toward eradicating canine rabies, since it does nothing to attack the disease in the host vector.

\section{Vaccinating dogs: the Latin American experience}

Progress toward eliminating canine rabies has been contrastingly rapid in nations that have emphasized preventively vaccinating dogs, even if the vaccination drives have not been followed up with systematic revaccination and vaccination of additions to the dog population. For example, "In a mass vaccination campaign conducted in Peru in March $1985,270,000$ dogs (65\% of the estimated dog population) were vaccinated over the course of one month with an inactivated tissue culture vaccine. Since that time, no human rabies cases have been reported. In addition, the number of animal rabies cases has declined to only three from a previous mean of 292 cases per year since 1980," a French team reported in 1988 [14]. Argentinean medical doctor Oscar Larghi confirmed during the mid-1990s that inexpensive threemonth dog vaccination drives could succeed in even the largest and poorest shanty-towns. Larghi reported to the members of the International Society for Infectious Diseases in May 1998 that "Control of rabies in developing countries can be very successful if based on appropriate planning, health education of human populations, $70 \%$ vaccine coverage of dog populations, and epidemiological surveillance”. These parameters, with little emphasis in dog population reduction (less than $10 \%$ of the estimated population), were applied in the metropolitan area of Buenos Aires, Argentina (10.5 million inhabitants), Lima-Callao, Peru (6.5 million inhabitants), and Sao Paulo, Brazil (14 million inhabitants). Dog rabies cases were reduced to zero, from close to 5,000 cases per year in Buenos Aires, 1,000 in Lima, and 1,200 in Sao Paulo.” In each city, the rabies control teams impounded and euthanized only dogs who appeared to be already rabid, aggressive, 
or otherwise severely unhealthy. Each city had, and still has, abundant free-roaming pet dogs, "community dogs" that are quasi-pets though not claimed by any one caretaker, and street dogs. Larghi's teams in 1995 vaccinated 1,230,000 dogs in Brazil alone $[15,16]$. As long ago as 1973, William Winkler, M.D., of the U.S. Centers for Disease Control and Prevention, warned in the National Academy of Sciences' handbook Control of Rabies, that "Persistent trapping or poisoning campaigns as a means to rabies control should be abolished. There is no evidence," Winkler wrote, "that these costly and politically attractive programs reduce either wildlife reservoirs or rabies incidence." Similar language has appeared ever since in the Compendium of Animal Rabies Prevention \& Control, an annual publication of the (U.S.) National Association of State Public Health Veterinarians [17].

"Widespread, sustained population reduction of mammalian reservoirs to eliminate rabies is not justified for ecologic, economic, and ethical reasons," agreed a four-member panel of Centers for Disease Control and Prevention scientists headed by Charles Rupprecht in 1995, after reviewing 50 years of progress toward eliminating rabies from both domestic and wild reservoirs in the U.S. [18]. So why is the failed and rejected strategy of attempted sustained population reduction still the most common response of local governments throughout much of the world, especially in Asia? The history of smallpox eradication offers a clue. The Wellcome Trust Centre for the History of Medicine stated that "If anything, the smallpox eradication program reveals the central importance of mobilizing local bureaucratic, political, and civilian support for public health programs reliant on large-scale immunization and isolation”. It also reveals the significance of adapting public health activity and messages to a plethora of local cultural mores and concerns, even though this policy is expensive." Translated into the context of rabies control, this means it is essential for those who would eradicate rabies to understand the historical, political, and economic evolution of the agencies and institutions responsible for controlling dogs, traditionally the main vector for rabies transmission to humans.

In addition, understanding the role of dogs in the urban ecology, especially so-called "stray” dogs, which fall into two major categories, free-roaming pet dogs and street dogs, is essential. Free-roaming pet dogs often wander, but are routinely fed by particular humans and tend to remain in proximity to their feeders. Street dogs (which dump dogs are a sub-set) tend to scavenge wherever edible refuse is discarded or rodents that may be caught. They typically have little direct contact with humans and tend to avoid human notice.

One World, One Health, One Medicine cofounder James Steele, M.D. explains, "The early concept of rabies was probably known by ancient civilizations of the Nile, Euphrates, Baghdad and Hindus River Valleys of India. The physicians and priests attributed the cause to meteorological conditions, mythological punishment, or the ingestion of a forbidden substance. The concept of contagion devolved from all these causes, consequence of violation of certain religious or spiritual taboos” [19].

\section{Historical methods of addressing the canine rabies vector}

Poisoning street dogs in response to rabies outbreaks appears to have begun early in the history of Pharaonic Egypt. Poisoning campaigns that caused dog populations to briefly crash might even have contributed to the conditions that drew African desert cats into Egyptian cities to hunt rats and mice approximately 8,000 years ago, though this can only be speculated in absence of any but scanty circumstantial archaeological evidence. Those cats became the progenitors of today's domestic house cats and feral cats. Their descendants eventually provided an early illustration of the futility of trying to lastingly eradicate any species where the habitat provides adequate food and cover. Under pressure of medieval cat purges, which coincided with the arrival of the Black Death in both Europe and southern China, domestic and feral cats approximately quadrupled their fecundity. The mummified remains of early Egyptian cats reveal that they usually had only two kittens per litter and one litter per year, like African desert cats, but modern house cats and feral cats often have litters of four or more kittens, and raise two litters per year if conditions permit [20].

Rabies control efforts, until the advent in recent decades of orally administered vaccines engineered to immunize wildlife, have focused on dogs, and in particular, exterminating dogs. This was the only known method of rabies prevention before the invention of vaccination. Therefore, they attempt to kill all possible hosts. The Prophet Mohammed is widely believed to have fought a rabies outbreak in 
the walled city of Medina by closing the city gates to prevent the outbreak from spreading, and then exterminating dogs. This is according to the order recounted by his disciple Bukhari in Hadith 4:540-a Hadith that perplexes Islamic scholars because Bukhari in particular was known to be fond of animals, and narrated several other sayings of Mohammed that urged kind treatment of dogs [21]. Killing suspected rabid dogs and other dogs who might become rabid was, and is, historically done by any of three means, mobilizing mobs to conduct short-term dog purges, delegating the work to law enforcement, or delegating the work to independent contractors. A fourth approach, the budka system, originating in Russia during czarist times, prevailed in Eastern Europe until the fall of Communism. Budka dog control was managed as a make-work activity for prison parolees. Animal control agencies, called budkas, were expected to support themselves by selling dog pelts, bone ash, rendered materials for fertilizer, even dog meat in some instances. Quite unpopular with the public, the budkas all but disappeared between 1990 and 2000, in favor of the same hodgepodge of programs run by cities, private contractors, and humane societies. However, the budka operators did not yield easily, inflicting considerable violence against the animal advocates who sought to displace them, including some suspected murder attempts [22]. The mob approach has most often been seen in recent years in China. In absence of standing animal control agencies, and sufficient police personnel to deal with perceived rabies threats, Chinese cities have throughout the Communist era (1949-present) periodically conscripted trash collectors and other lowranking civil servants to purge dogs in sweeps conducted for a few days or a week, rarely longer. Post-2006, however, there has evolved a trend in China, encouraged by the central government, toward professionalizing animal control. Animal control was professionalized in Beijing, the Chinese capital city, several years earlier. The professionalization proved to be considerably more popular with the public, and much more efficacious in suppressing the dog population at large, than the notoriously brutal sweeps that were formerly practiced [23].

Delegating dog-killing to law enforcement long predates the origin of modern municipal police forces in the early $19^{\text {th }}$ century, and appears to predate as well the origin of constabulary law enforcement by elected officials, several centuries earlier.
Before the widespread introduction of representative forms of government, killing problematic dogs was typically assigned to gamekeepers in the countryside, and to night watchmen in urban communities, who were usually mercenary soldiers between wars. These men were members of the militias maintained by feudal warlords. Their primary duty was maintaining their employers' security. Killing dogs was of secondary importance to controlling human troublemakers. The work of dog control evolved from this beginning in two directions. One direction was the delegation of killing suspect dogs to constabulary agents. These agents, in U.S. small towns, usually had multiple duties. A fictional example of how this system worked, closely based on actual events that occurred in Alabama in 1932 to 1936, will be remembered by millions of readers and viewers of the film version of Harper Lee's classic 1960 novel To Kill A Mocking Bird. The hero, Atticus Finch, is the community public defender. As such is, he is assigned to shoot a rabid dog. Alternatively, killing dogs might be subcontracted by government to individuals, for-profit companies, or nonprofit agencies. Until the mid-20th century, this approach prevailed only in cities of medium size or larger. Smaller communities did not have enough problematic dogs to keep fulltime dogcatchers occupied. Evolving directly from the feudal practice of hiring mercenaries, the process of hiring individuals, businesses, or nonprofit agencies was, and is, closely associated with the dispensation of patronage jobs and contracts. For-profit dogcatchers became controversial in Europe and North America early in the 19th century, initially in connection with the side business of supplying dogs for medical experimentation [24]. Humane attention to the uses of dogs that were captured and sold led to concern about the methods used to kill those who were not sold [25-27].

Nonprofit agencies became directly involved in rabies control beginning in 1877, when the Women's Humane Society of Philadelphia took over the Philadelphia pound to halt the practices of clubbing and drowning dogs and cats [28]. American Society for the Prevention of Cruelty to Animals (SPCA) founder Henry Bergh, an outspoken opponent of indiscriminately killing dogs for rabies control, resisted pressure to take over the New York City pounds, accurately perceiving that the job would sap the ability of the ASPCA to do effective anti-cruelty advocacy. However, seven years after Bergh's death, the 
ASPCA did assume the pound job and held it for the next 100 years, killing more than a quarter of a million dogs and cats per year in the 1960s, mostly by gas [29]. U.S. humane societies increasingly felt themselves compelled to take responsibility for animal control sheltering from the late 19th century until the late 20th century, after municipal policymakers discovered the persuasive effect on humane donors of selling or threatening to sell animals to laboratories. Thus, much of the expense of animal control was transferred from municipal budgets to people who were concerned about preventing animal suffering. The American Humane Association (AHA), as the only national humane society in the U.S. before the mid-1950s, responded by urging humane societies to take animal control contracts. Paradoxically, to boycott compulsory rabies vaccination, as vaccine development and production were perceived as unacceptably cruel to laboratory animals and to the sheep whose brains were then used as the medium for cultivating the vaccines [30]. This position appears to have been dropped more-or-less by default by the 1960s, after a decade or more of AHA silence on the subject while emergent rival organizations energetically promoted vaccination. For much of the $20^{\text {th }}$ century, the main work of U.S. humane societies came to be killing dogs and cats by the multi-million, in the names of rabies control and population control. The toll rose from circa two million dogs and cats killed in 1950, in approximately equal numbers, to circa 23 million per year killed in the early 1970s, when increasing public acceptance of dog and cat sterilization and the emergence of low-cost clinics to make the surgery affordable began to drive the toll down. Currently, all U.S. animal shelters combined kill is under four million dogs and cats per year, still about equal numbers of either species, including approximately 600,000 dogs found running at large [31]. The practice of selling pound dogs and cats to laboratories is believed to have peaked before the passage of the 1966 Laboratory Animal Welfare Act, which was amended into the present Animal Welfare Act in 1971. More than 300 for-profit dealers sold upward of 300,000 impounded dogs and cats per year to labs at that time to fewer than 10 do today with total annual sales volume under 1,000 dogs and cats [32]. Since the early 1990s, much of the U.S. humane community has returned rabies control duties to municipal management.

\section{Conflicting economic interests}

U.S. humane societies most often won animal control contracts when animal control contracts were offered for bidding. In communities where vendors operating for profit won the animal control contracts, decades of litigation, political campaigning, and violent conflict sometime followed, as animal advocates sought to dislodge the for-profit contractors while the for-profit contractors fought to hold their businesses. In one state, Michigan, conflict between animal advocates and some of the last for-profit animal control contractors continued into the $21^{\text {st }}$ century [33]. For-profit animal control contractors in the developing world rarely sell dogs to labs, since there is relatively little lab demand for random-source dogs in the bioengineering era in which knowing the genetic history of experimental subjects is often essential. However, Asian dogcatchers have frequently developed other markets. For example, selling impounded dogs for human consumption is commonly alleged in the Philippines and Indonesia, albeit rarely acknowledged [34]. Selling dog leather was common among animal control contractors along the Bengal coast of India before humane societies wrested away the contracts in the late 1990s. In Visakhapatnam the disenfranchised dog-leather dealers on Christmas Eve 1999 roused a mob, stormed the Visakha SPCA clinic, and destroyed the clinic equipment [35]. The political and economic role of dogcatchers and dog catching agencies must be understood and, if possible, accommodated in introducing rabies control through vaccination. Otherwise, dogcatchers and dog catching agencies tend to fear and resist the loss of their livelihoods. Even if hired to catch dogs for vaccination, or for vaccination plus sterilization, dogcatchers and dog catching agencies may sabotage the success of vaccination programs if they believe that success will put them out of business- including by killing or campaigning to kill dogs that have already been vaccinated. Politicians who employ dogcatchers meanwhile tend to resist the perceived loss of patronage jobs, which can be dispensed to supporters of low education, whose votes, community influence, and election campaign muscle, are often much more valuable than their limited job skills. Opposition may also arise from people involved in side industries, such as selling the remains of impounded dogs for human consumption, whose customers may include persons of political and economic power. 
A related issue is that while capturing and killing dogs have historically been considered men's work, vaccinating dogs tends to employ proportionately more women. Thus, gender-related economic and social factors may influence the success of a rabies vaccination or dog sterilization campaign.

\section{Understanding urban animal ecology}

Policymakers have pursued self-defeating animal control strategies since the dawn of civilization primarily because the logic of exterminating animals that are perceived as nuisances appears inescapable. The policy-makers reason that dead animals do not reproduce. Neither do dead animals transmit deadly diseases, like rabies, which can only be spread through live hosts. In addition, the existence of a market for meat, pelts, and/or other body parts tends to ensure that animals are verifiably destroyed, whereas, it is possible for unscrupulous agents to fake a vaccination.

Yet life had already evolved a counter-strategy to defeat intensive predation or population losses due to disease and natural disaster long before humans existed. All species, from the rabies virus to blue whales, reproduce up to the carrying capacity of their habitat, as rapidly as possible. If one species succumbs to disease, disaster, or predation so rapidly that it cannot fill the habitat, another species moves in. Never does nature allow habitat to go unoccupied. Until the carrying capacity of cities for free-roaming mid-sized predators and scavengers is permanently reduced by instituting effective sanitation, campaigns to exterminate street dogs, feral cats, or any other established resident species merely exchanges those animals for others. Killing dogs and cats not only removes a major check on the growth of the rat and mouse population, for instance, but invites in more problematic species to take their places. Many Asian cities now have hard-to-control populations of feral pigs, macaques, and even jackals, leopards, and cobras in their suburbs, in consequence of rapidly reducing dog populations through sterilization in the more enlightened communities, and elsewhere through the combined effects of extermination and great increases in motor vehicle traffic [36].

Policymakers in the developing world, supported by the factions with an economic interest in killing dogs, often seek for their cities the superficially animalfree appearance of a "modern" city that they see in Europe and the U.S., equating this with ridding themselves of rabies. However, casual outdoor observation of European and U.S. cities by daylight is deeply deceptive. European and American cities support even more dogs, cats, and wild animals per thousand humans than the cities of the developing world. They have merely achieved a transition from hosting outdoor animals, seen in daytime, to hosting mostly indoor pets and nocturnal wildlife. Motor vehicles, rather than any animal control strategies, appear to be the major transition agents. Motor vehicle traffic reduces street dog populations by killing dogs, obviously enough, but this is the least of the vehicular impacts, and is no different in effect from animal control killing. Busy streets also isolate dogs from each other, inhibiting reproduction. Most important, replacing urban grain storage for work animals with gasoline stations steeply reduces the numbers of rats accessible to dogs. Replacing work animals with cars and trucks also eliminates animal droppings from the streets, an important "filler" food for street dogs [37].

As street dogs disappear, ceding scavenging roles to raccoons and opossums in the U.S., and pigs and monkeys in much of the rest of the world, feral cats proliferate. The same factors affect the cat population, but cats are smaller, so are better able to survive on the remaining food sources, without canine competition. Cats are also better able to prey upon mice and rats that live indoors, and cats are able to spend their days away from traffic on rooftops or in crawl spaces, hunting by night. If feral cat populations steeply diminish, as has occurred in the U.S. and Britain during the past 15 -20 years through the introduction of feral cat sterilization programs, the habitat niches that the cats formerly filled are taken over by urbanized wild predators including coyotes, foxes, fishers, bobcats, hawks, owls, and eagles, all of whom are more abundant now in U.S. suburbs than in any other habitat. However, neither dogs nor cats actually decline in numbers, as illustrated by comparing data collected by pioneering dog and cat population ecologist John Marbanks in 1947-1950, when canine rabies still raged in the U.S., to the findings of more recent studies [38].

In the late 1940s and early 1950s, post-World War II, the mechanization of transportation and establishment of urban sanitation were in the U.S. at stages of evolution similar to the conditions prevailing today in the developing world. Not surprisingly, Marbanks found that about a third of the U.S. dog population-10 million of 32.6 million-were homeless and free-roaming. Another 12 million rural dogs also 
mostly enjoyed freedom to roam. About 30 million cats were feral. Only about 10.5 million urban dogs could be presumed to be kept mostly in some sort of confinement. Marbanks' findings indicated that there were only 600,000 street dogs in the already heavily motorized U.S. Northeast, but were 3.5 million in the U.S. South and 2.3 million in the U.S. Midwest, the two most agrarian parts of the U.S., which also happened to have the most canine rabies. By 1975, Robert H. Wilbur of the Pet Food Institute reported to the National Conference on Dog \& Cat Control, the U.S. pet dog population had increased to 41.3 million, a $45 \%$ increase since 1950 . Street dogs had almost completely disappeared from the U.S., but at least $24 \%$ of dog keepers not only allowed their dogs to roam at large but also admitted to having lost a free-roaming dog. Thus, the number of dogs at large at any given time appears to have been not less than were at large 25 years earlier [39]. Yet canine rabies had all but vanished. An enormous change had transpired, but a change in the exposure of freeroaming dogs to canine rabies, not in the absolute numbers of dogs at large. Unvaccinated street dogs had been replaced by an almost equal number of vaccinated pets. Were the street dogs exterminated? Some certainly were, but road-kills appear to have killed more dogs than animal control agencies [40]. The number of cars and miles driven in the U.S. tripled between 1950 and 1975. Though this led to a visible increase in the number of animals killed on highways, leading to the first formal studies of road-kill toward the end of the 1950s, the major effect of mechanization of transport, together with improvements in urban sanitation, was to reallocate the carrying capacity of the human environment. Instead of supporting dogs and cats that lived directly from refuse and rodents, the human environment evolved to support dogs and cats that lived on refuse processed into pet food, fed to them in human homes.

This same reallocation of carrying capacity occurred in Western Europe at about the same time, and is occurring now in Eastern Europe, India, China, Indonesia, and wherever else economic development is transforming former hubs of agrarian commerce into technologically developed modern cities. The final eradication of canine rabies in the U.S. did roughly coincide with allowing pet dogs to roam, becoming socially unacceptable, which occurred mostly after 1975. However, by far the greatest part of canine rabies eradication in the U.S. was achieved through aggressive promotion of vaccination, mostly between 1945 and 1955, while the U.S. population of dogs roaming at large was still as big as it had ever been.

\section{The British experience}

That leaves only one nation, Britain, where canine rabies is widely believed to have been eradicated through the traditional prescriptions of aggressive population reduction and quarantine, without intensive dog vaccination. Yet, much of the history of British rabies eradication may have been lost to public health and veterinary literature through the hostility of the British scientific and humane sectors during the years when it occurred. Therefore, information about successful contributions to the eradication effort simply was not shared.

Enmity developed when the scientific establishment lobbied successfully for exemptions to the Anti-Cruelty Act of 1876. The subsequent erosion of communication and cooperation between the scientific and humane sectors culminated in the Brown Dog Riots, which broke out annually near University College, London, from 1902 until 1910. The initial grievance over the use of dogs at University College was further inflamed after British National AntiVivisection Society President Stephen Coleridge was convicted of libel for his description of the death of a small brown terrier at a 1903 public meeting [24, 41]. Mid-19th century rabies outbreaks meanwhile led to repeated dog purges, especially in London, and to the 1867 passage of the Metropolitan Streets Act, which authorized police to "seize all vagrant dogs." After 20 years of this policy that failed to stop canine rabies, the Rabies Order of 1887 required that all dogs be muzzled and leashed when in public [42]. This also appears to have accomplished little, except to goad the Lady Gertrude Stock and a "small party of gentlemen" to form the National Canine Defense League on February 12, 1891, specifically to discuss ways and means of accomplishing humane rabies control. "They were as one," according to the authorized history of the National Canine Defense League, "in believing that the 'dog scares' were nothing more than mischief put out by 'persons interested in the establishment and maintenance of Pasteur Institutes'--laboratories in France and Britain dedicated to pursuing research into the anti-rabies vaccine discovered by Louis Pasteur in 1885, for which purpose they sought a steady supply of dogs on which to experiment.” [43]. The National Canine Defense 
League at inception was not only an anti-vivisection society but also an anti-vaccination society. However, it was also an anti-rabies society. It immediately undertook three projects of value in curtailing rabies and rabies scares. One was to immediately locate dog bite victims and wash their wounds, a seemingly simple, obvious procedure, which until then, had never been promoted in a systematic manner. Another NCDL contribution was to dispatch physicians to investigate all reports of rabies outbreaks. Many proved to be misreported, involving bites by healthy dogs and/or dogs that were ill from other diseases. Though this did not reduce the actual number of rabies cases, it reduced the numbers that were claimed, and contributed to recognition that rabies was disappearing. The third NCDL anti-rabies activity was to educate and campaign against keeping dogs chained, in the belief that chained dogs are more likely to be bitten by rabid animals because they cannot escape, and are in turn more likely to bite a person who is perceived as a threat, again because they cannot run away. These beliefs were validated by behavioral research more than 90 years later [44]. The last human death from canine rabies in Great Britain occurred in Wales in 1902, but canine rabies persisted among dogs for 20 years longer. Meanwhile the NCDL skirmished annually in Parliamentary debate against the British scientific establishment and dog-catching agencies over the legislation that became the Dog Law of 1910, instituting dog licensing and vaccination requirements. As the law came to be strictly enforced during World War I, and afterward during a resurgence of canine rabies in 1918-1922, the NCDL began subsidizing the cost of dog licensing for poor families. NCDL clinics established throughout Britain became the leading providers of canine rabies vaccination, a paradox in view of the origins of the society. Circumstantial evidence suggests that it was the NCDL vaccination program to which Contra Costa County livestock commissioner J.J. Hogarty referred in his 1922 speech to the county commissioners advocating vaccination. The last of the NCDL clinics closed in 1987, by which time the organization had long since refocused upon re-homing lost and abandoned dogs. In 2003, the organization changed names, and is now known as Dogs Trust.

\section{Recent Asian experience}

There is no major example of canine rabies eradication without intensive dog vaccination.
Furthermore, there is no major example that credibly demonstrates that killing dogs, or even eliminating free-roaming dog populations, contributed anything substantive to rabies eradication. It only opens the habitat niches to new generations of unvaccinated dogs, who may become rabies vectors if infected. Conversely, vaccinated dogs are not rabies vectors, regardless of where or how they live. The effort and funding invested in endlessly killing dogs, if put into vaccinating dogs instead, could rapidly eradicate canine rabies by ensuring that herd immunity exists among all dog populations. Instead, the present Asian situation includes doing frequent dog extermination campaigns, which do little but perpetuate rabies outbreaks by killing free-roaming dogs who have already been vaccinated. This problem may have been most dramatically evident in Bangalore, India, in 2007. The Bangalore humane societies Compassion Unlimited Plus Action, the Animal Rights Fund, Krupa, and Karuna, operating federally subsidized Animal Birth Control programs cited as positive examples by World Health Organization chief veterinary officer F.X. Meslin, had entirely eliminated rabies from their service areas and had brought the dog population down markedly as well. In early 2007, however, Bangalore city officials wrongly blamed alleged failures of the ABC programs for two fatal dog attacks. Subsequent investigation established that these attacks actually occurred chiefly because the Bangalore municipal government failed to stop butchers in areas outside the ABC program limits from dumping meat wastes in vacant lots, which then attracted dogs. This failure occurred despite repeated warnings from the Animal Rights Fund [45]. The officials' attacks obliged the Bangalore humane societies to suspend their ABC work, including anti-rabies vaccination of dogs, and severely harmed their ability to raise funds to resume. Poor administration of the Bangalore municipal animal control program meanwhile allowed rabies to reinfiltrate the city. Similar episodes have repeatedly in 2009 to 2011 inhibited the success of the Bali Animal Welfare Association (BAWA) vaccination campaign, funded largely by the World Society for the Protection of Animals, with additional help from the Australian government, and the International Fund for Animal Welfare. Vaccinating 210,000 dogs in the six months ending on March 31, 2011, amounting to more than $70 \%$ of the Bali dog population, BAWA accomplished a $48 \%$ reduction in human rabies deaths and a $45 \%$ decrease in dog rabies cases. This was the fastest 
containment of a rabies outbreak in the history of Indonesia, achieved even as a 13-year-old outbreak continues in Flores, where officials have fought rabies mainly by culling dogs [46]. However, after human rabies deaths have resulted from dog bites that occurred months before the BAWA vaccination teams reached particular communities, local and regional government agencies have responded by killing any dogs that they could catch in those communities, regardless of the dogs' vaccination status. The Balinese central government eventually signed a Memorandum of Understanding with BAWA and international funding agencies to stop culling dogs and promote vaccination strategies. However, the MOU was inconsistently observed, especially in Klungkung regency, where dog culling continued and rabies cases are still reported. The MOU expired recently, as of this writing. The vaccination program and funding are under renegotiation.

\section{Conclusion}

Vaccination success builds on success, increasing the immunized portion of the target population. Canine rabies can be eliminated worldwide, just as smallpox was, but only when policymakers properly understand what the effort requires.

\section{Acknowledgement}

The author and editors would like to thank "Henry Luce Scholar" Henry Cheng for very helpful suggestions and editorial assistance. The author is the editor of a newspaper, which covers animal welfare worldwide. He has no conflicts to declare.

\section{References}

1. Henry Wilde, Thiravet Hemachudha, Pakamat Khawplod, Veera Tepsumethanon, Supaporn Washarapluesadee, Boonlert Lumlertdacha. Rabies 2007: perspective from Asia. Asian Biomedicine: 2007; 1:345.

2. Rabies 'could be gone' in decade. BBC News. [cited September 8, 2007]. Available from http://news.bbc. co.uk/2/hi/uk_news/scotland/edinburgh_and_east/ 6983384.stm.

3. The Welcome Trust Centre for the History of Medicine at University Collage of London. The control and eradication of smallpox in South Asia. [cited July 18, 2006]. Available from http://www.smallpoxhistory.ucl. ac.uk/.

4. Rabies vaccination for dogs urged for county.
Oakland Tribune, July 23, 1922.

5. Issue dog tags minus vaccine. Tucson Daily Citizen. March 7, 1949.

6. Irked county may ‘Order’ dog shots. Syracuse HeraldJournal, July 15, 1951.

7. Phillip Rawls. Rabies spreads as vaccinations decline. Associated Press. June 3, 2005.

8. Complacency raises rabies risk. Yomiuri Shimbun. April 3, 2007.

9. Reid-Sanden, Frances L., Dobbins, James G., Smith, Jean S., Fishbein, Daniel B., Rabies surveillance in the United States during 1989. J. Am. Vet. Med. Assoc. December 15, 1990.

10. Maggie Fox. U.S. free of canine rabies virus. Reuters. September 7, 2007.

11. Bite treatment producers prepare for monsoons. Animal People. June 2001.

12. Bogus vaccines contribute to human rabies death toll in China. Animal People. July/August 2007.

13. Rabies vaccine recalled for having illegal ingredient. Xinhua News Agency. February 7, 2009.

14. Chomel B, Chappuis G, Bullon F, Cardenas E, de Beublain TD, Lombard M, Giambruno E. Mass vaccination campaign against rabies: are dogs correctly protected?. The Peruvian experience. Review of Infectious Diseases. 1988; Suppl 4:S697-702.

15. ProMed Archive Number 19980518.0956. [cited May 18, 1998]. Available from http://www.promedmail.org/ pls/otn.

16. WHO. Annex 5: Vaccine application to dogs and oral immunization against rabies, World Survey of Rabies \#31 for the year 1995. Available from http://www.who. int/emcdocuments/rabies/docs/wsr95/wsr95_a5.html.

17. National Association of State Public Health Veterinarians, Inc. Compendium of Animal Rabies Prevention and Control 2008. Available from http:// www.cdc.gov/mmwr/preview/mmwrhtml/rr5702a1.htm.

18. Charles E Rupprecht, Jean S Smith, Makonnen Fekadu, James E Childs. The ascension of wildlife rabies: a cause for public health concern or intervention? Emerg Infect Dis. 1995; 1: 107-113.

19. James H. Steele. The early history of rabies, University of Texas School of Public Health. Accessible at http://www.slideshare.net/drdgmmrm/ rabies-newsletter-2570899.

20. How to eradicate rabies in 10 years or less. Animal People. September 2007.

21. Merritt Clifton. What did the Prophet Mohammed really say about dogs?. Animal People. January/ February 2008. 
22. Merritt Clifton. High-energy post-Soviet activists do everything but raise money. Animal People. January/ February 2003.

23. Merritt Clifton. Animal control changing in China. Animal People. September 2006.

24. Roberta Kalechovsky. The poet-physician \& the healer-killer: vivisection \& the emergence of a medical technocracy. Micah Publications; 2009.

25. Mr. Bergh and the dogs. The New York Times. September 17, 1868.

26. Disgusting brutality: killing dogs in the St. Louis dog pound. The New York Times. July 19, 1877.

27. The doomed dogs. The New York Times. June 26, 1879.

28. William Alan Swallow. Quality of Mercy. American Humane Education Society; 1963.

29. Marion S Lane, Stephen L Zawistowski. Heritage of Care: The American Society for the Prevention of Cruelty to Animals. Praeger Publishers; 2008.

30. This topic was repeatedly addressed in National Humane Review editorials published between 1923 and 1940 .

31. U.S. progress against shelter killing. Animal People. July/August 2010.

32. Allie Phillips. How shelter pets are brokered for experimentation: understanding pound seizure. Rowman \& Littlefield Publishers Inc.; 2010.

33. Jackson County stops selling pound animals to labs. Animal People. September 2006.

34. Merritt Clifton. Move to reinstate tailpipe gassing in the Philippines. Animal People. May 2011.

35. Merritt Clifton. Courage, compassion required of Bengal coast animal rescuers. Animal People January/ February 2001.

36. Merritt Clifton. The science of trap-neuter-release, paper presented at Asia for Animals Conference; Hong Kong, 2003.

37. An accurate understanding of the relationship of traffic to street dog population requires avoiding confusing intense traffic congestion with the accomplishment of a transition to near-complete reliance on mechanized transport. Intense traffic congestion, common in much of the developing world, typically results from the introduction of motor vehicles to urban infrastructure not designed to accommodate high-speed traffic and the need to park motor vehicles, where streets continue to be occupied by pedestrians, pushcarts, pedal-powered vehicles, and animal-drawn vehicles. Such congestion begins at a volume of motorized traffic which remains far below the volume of motorized traffic seen in the U.S. and Europe, where urban infrastructure was rebuilt during the 1950 s to accommodate mechanization. A study of relevance is: Kenworthy, Jeff, Automobile Dependence in Bangkok:An International Comparison With Implications for Planning Policies and Air Pollution, Institute for Sustainability and Technology Policy, Murdoch University, Australia, 2000; [cited May 29, 2011]. Available from http://www.istp.murdoch.edu.au/ISTP/ casestudies/Case_Studies_Asia/bangkok/bangko k.html.

38. John Marbanks. Going to the dogs (and cats). National Humane Review, January 1954. "John Marbanks” appears to have been a pseudonym used by the collaboration of National Family Opinion Inc. founders Howard and Clara Trumbull, who were also known to use a variety of other pseudonyms for their extracurriculular projects.

39. Robert H Wilbur. Pets, pet ownership and animal control: social \& psychological attitudes. Proceedings of the National Conference on Dog \& Cat Control; February 3-5, 1976; Colorado, USA.; 1976.21.

40. Merritt Clifton. Cold winter holds down roadkills. Peaks coincide with moon phases. Animal People. September 1994.

41. Richard Ryder. Animal Revolution, Berg Publishers; 2000.

42. Neil Pemberton, Michael Warboys. Mad Dogs and Englishmen: Rabies in Britain 1830-2000. Basingstoke: Palgrave Macmillan; 2007.

43. Peter Ballard. A Dog Is For Life: Celebrating the first 100 years of the National Canine Defence League, National Canine Defense League 1990.

44. http://www.dogsdeservebetter.com/articles.html offers a considerable collection of information from both popular and scholarly sources about the effects of chaining on dog behavior.

45. Hiranmay Karlekar. Savage Humans \& Stray Dogs. Sage Publications; 2008.

46. Island-wide Dog Vaccination Campaign in Bali Significantly Decreases Rabies Cases. PRNewswireUSNewswire. April 5, 2011. 